\title{
Building a Thematic Spatial Data Infrastructure and Situation-Aware for Global Events
}

\author{
Wellington M. Oliveira1 ${ }^{1}$, Jugurta Lisboa-Filho*2, Alcione P. Oliveira², Wagner D. Souza ${ }^{2}$, Lucas F. \\ M. Vegi², João R. M. Oliveira ${ }^{2}$ \\ ${ }^{1}$ Instituto Federal de Educação, Ciência e Tecnologia do Sudeste de Minas Gerais, Rio Pomba, Brazil. \\ 2 Universidade Federal de Viçosa, Viçosa-MG, Brazil. \\ * Corresponding author. Email: jugurta@ufv.br, wellington.moreira@ifsudestemg.edu.br, alcione@dpi.ufv.br, \\ wagnerdiasdesouza@gmail.com, lucasvegi@gmail.com, joao.menighin@gmail.com \\ Manuscript submitted January 10, 2014; accepted March 8, 2014. \\ doi: 10.17706/jsw.10.3.304-316
}

\begin{abstract}
The Brazil hosted the FIFA World Cup in 2014, a sporting event of great magnitude that attracts thousands of people from many countries around the world. The Brazilian government created several initiatives on physical and also virtual infrastructure to be able to cope with this mega event. This paper presents an e-Government initiative composed by an infrastructure to supply data and information to thousands of supporters and professionals involved with the World Cup. This initiative is described here from the perspective of a Thematic Spatial Data Infrastructure (TSDI) using context information based on an ontological model. This infrastructure provides relevant information about events location and interesting services for user. In this infrastructure, the user can also voluntarily provide spatial information about events and services linked to the World Cup.
\end{abstract}

Key words: Spatial data infrastructure, VGI, situation aware, ontology, football world cup.

\section{Introduction}

In 2014, Brazil hosted the FIFA World Cup. Thus, since the year 2012 the Brazilian government in partnership with the private sector, created plans and strategies to assist and support the millions of tourists and professionals, Brazilians and foreigners. This infrastructure has a huge necessary items list. It includes the construction and modernization of stadiums, transportation, public safety, accommodation, food, information and communication technologies, among others. The planned investments in this infrastructure are around US $\$ 14.8$ billion with the prediction of an injection of US\$ 71.19 billion in the Brazilian economy between the years 2010 and 2014, according to a survey by Ernst \& Young in partnership with Getúlio Vargas Foundation [1].

The media gave more attention to investments and targeted to the physical infrastructure. However, some services offered by information and communication technologies, such as information systems, which can be considered as "virtual infrastructures", play an important role to supporting the participants in this mega event. Information systems that integrate spatial data can be useful for people in constant movement between cities hosting in international events. These systems, known as Geographic Information Systems (GIS), are intended for the manipulation, analysis, integration and generation of spatial information.

Any e-Government initiative exists to provide governmental information to general citizens by means of the integration of public services contents and promptly respond to public demands with the support of information technology [2]. This paper proposes an e-Government initiative composed by a structure that integrates GIS and other technologies besides various patterns and institutional arrangements called Spatial Data Infrastructure 
(SDI). These infrastructures allow user to have easy access to a range of spatial data by searching on metadata catalogs, which are normally provided by a geoportal [3].

The coverage of SDIs can encompass regions, states, provinces, countries or even continents. In addition to meeting the regional coverage, SDIs can be related to a specific community of users, as is the case of this work that proposes the creation of a World Cup thematic SDI. As each participant has its own preferences and habits, it is important to consider these SDI features, and the environment that it is inserted. This enables the user to search more clearly and fast data of interest. This "situation-aware" can be obtained by ontological mapping entities in the World Cup domain and by registering each user's preference as language, home country, search radius and schedule of event occurrence.

Thus, this paper describes the project of creating a Spatial Data Infrastructure, accessible via a geoportal, with support for different languages. It allows users access the spatial information of interest about events related to World Cup and about infrastructure for their accommodation, food and transportation. The user may also voluntarily contribute with new data and spatial information related to the World Cup, acting as "human sensors" [4] and thus enriching the spatial database. This project also can be customized for another international event, for example, the Olympic Games.

The official term for the event was "2014 FIFA World Cup Brazil", in this paper we chose to use the following abbreviated expressions Cup, World Cup, 2014 World Cup, as it is the single focus of this work. The official term is mandatory for marketing purposes, according to FIFA's official website.

This paper is organized as follows. Section 2 describes the theoretical frame of reference and some related work. Section 3 presents the modeling and implementation of situation-aware thematic SDI for the 2014 World Cup. Some final considerations are described in Section 4.

\section{Theoretical Frame of Reference and Related Work}

The large volume of spatial information currently available brings a great challenge with regard to its management, storage and discovery, directly affecting the availability and access. Today there are spatial data sources scattered across the globe that are manipulated by GIS and stored in heterogeneous geographic databases. Data redundancy is another major problem that can also happen with the lack of a proper management to collect and manage this large amount of information. It is in this context that SDIs are presented as a proposal for improving the management, sharing and making it easier to access the spatial information for various user communities.

SDIs are typically controlled by public organizations that establish laws and agreements that guide its implementation. According to [5], the development of a SDI involves technical and non-technical elements for the exchange, distribution and sharing of spatial data in a progressive process of negotiations and alignments between heterogeneous actors within a specific context. In addition, a SDI is not something that can deliver a final product or an artifact. Furthermore, it should be seen as an evolving process.

SDIs have offered support to numerous projects and ventures, where the accessibility and usability related to the spatial information and its associated services are the key requirements. A SDI holds data from multiple suppliers and distributes transparently over the network [6].

SDIs can operate at different levels: global, national, regional or local [7]. In Brazil, there are many regional and local initiatives of SDI. At the national level, the Infraestrutura Nacional de Dados Espaciais (INDE) is defined as follows:

"An integrated set of technologies, policies, procedures and mechanisms for coordination and monitoring; standards and agreements required to facilitate and organize the generation, storage, access, sharing, dissemination and use of geospatial data source federal, state, district and municipal" [8].

The National Commission of Cartography (CONCAR) is responsible for implementing the INDE and holds spatial information about the Brazilian territory. Geographic data are documented through metadata, or data about geographic data [9]. In the case of INDE, metadata is standardized according to the MGB profile (Brazilian 
Geographic Metadata) that is in conformity with ISO 19115:2003.

Fig. 1 shows SDI dynamic environment where people use technologies structures, standards, policies and institutional arrangements to access geographic information. This last item occupies a prominent position because it is the basis of all SDI. The geographical information describing, for instance, anthropogenic environmental factors, measures of air quality, place names, cultural information, among others.

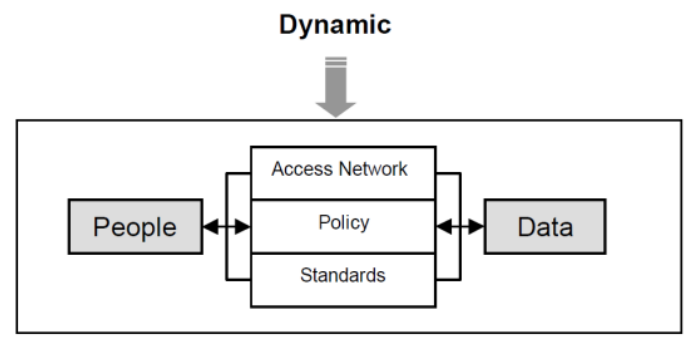

Fig. 1. SDI Components and their relationships [10].

One of the main features of a SDI is to provide answers to user communities seeking information with geographic attributes. According [9], features of a SDI follow a life cycle, as illustrated in Fig. 2. This life cycle begins with the publishing of resources on SDI, making them available to other interested parties. In the second phase, these resources are searched and discovered. The third phase includes the ability to access and view discovered resources. Finally, in the last step, users process and exploit them, generating new information that should be ready for publication in SDI, closing the cycle.

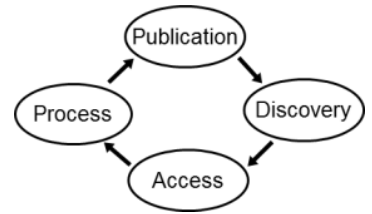

Fig. 2. Lifecycle of SDIs resources.

Geographical information cannot always be captured (i.e.: through remote sensing images). Geographic information voluntarily provided by users, also called VGI (Volunteered Geographic Information), presents a solution with great coverage, because it has more than six billion sensors: all terrestrial population spread across the globe [4].

A good example of VGI application is the Open Street Map that has tens of thousands of data sources provided by users with or without previous experience in geographic information. Still lacking mechanisms to ensure the quality of this information, remove errors and presenting some level of confidence. On the other hand, volunteering appears as the only solution to the decline in the supply of geographic information with government resources worldwide [4].

For creating a situation-aware SDI, we need to consider user preferences, mapping of the World Cup environment through a domain ontology as well as to record user preferences information together with a selection of his role (e.g., football player, supporter, coach, etc). According to [11], on Computing Science context, ontology is an explicit formal specification of a shared conceptualization. This type of mapping is useful for modeling World Cup environment, allowing users to retrieve only information of this geographical domain.

According [12], ontology-based computing has recently shown a tendency to develop a process model for context information based on computer. In the same sense, the taxonomy of basic categories proposed by [13], which comprises the ontology DOLCE (Descriptive Ontology for Linguistic and Cognitive Engineering), can be used as a basis for a context model. This choice is due to the decrease in the gap between the domain of lexical and conceptual modeling technologies that provides descriptive ontology [13].

The Semantic Web language OWL (Web Ontology Language), which is based on RDF (Resource Description Framework), supports logic to formalize ontologies. OWL is a standard recommend by W3C. It has been widely used as a language of formal ontological concepts [14]. 
Besides providing access to data, a SDI can also offer various services, from a simple query to a query encompassing such as the metadata geoprocessing services, displaying maps and location of entities based on coordinates. Web Services ensure that these services are available to a greater number of people and systems in a distributed and collaborative way. This technology not only provides independent services, it supports collaborative work where basic services designed for a certain operation can be connected to form a larger service [15].

Aiming interoperability of services in the geoprocessing area, the Open Geospatial Consortium (OGC) standardizes specifications for Web services that manipulate geographic data, known as OWS (OGC Web Service). This standard allows for connection of multiple Web services that compose a dynamic application [15].

Ontologies have been used in situation-aware systems, related to other major events. One example is the work published by [16] which used a context model for providing context-aware mobile services for the Beijing Olympics 2008. [17] proposes a mobile GIS contextaware to assist students, faculty, staff and visitors to find events and university sectors. In their work, models and architectures have been developed to support location services also based on the user's environment. The work of [18] discusses techniques used in recommendation systems to handle user profiles. Unlike the present study, which is based on ontological models, Barth makes free use of stereotypes for modeling the recommendation system.

Most of these work abovementioned deals with GIS situation-aware or recommendation systems, which may even be improved and applied to other major events like the World Cup. However, none of them makes use of the availability of data and metadata services by means of SDIs. According [19], a SDI directed to a specific community of users is called Thematic Spatial Data Infrastructure (TSDI).

\section{SDI-Geocopa: Modeling and Implementation of a SDI Situation-Aware}

The development of models that help us to abstract and understand the reality must anticipate any large software implementation. For this paper, models were developed to enable a better understanding of the application domain related to major events. Since we implemented a Thematic SDI (SDI-geoCopa), whose architecture, models, tools and technologies are described in the following subsections.



Fig. 3. Architecture of a SDI situation-aware

\subsection{Architecture of a SDI Situation-Aware}

SDI-geoCopa uses a web application interface that makes use of a GPS, and that failing, prompts the user to define its geographical position. The information processing is performed by web services according to OGC standard. Fig. 3 illustrates SDI-geoCopa architecture with their respective components described next.

SDI-geoCopa uses a web application interface that makes use of a GPS, and that failing, prompts the user to define its geographical position. The information processing is performed by web services according to OGC standard. Fig. 3 illustrates SDI-geoCopa architecture with their respective components described next.

\subsubsection{Application layer}

The application layer comprises the Web application and the component GPS location, as described following:

- Web Application: comprises an interface that supports more than one language that prompts the user for an 
username and password and displays information on its location and other context information, such as events services of interest. The user can upgrade on the fly his preference list or search on other events or services. Being the web application multiplatform by nature, besides computers, notebooks and tablets, other mobile devices like palmtops and mobile phones containing browsers with support for HTML, JavaScript and CSS will have access to SDI anywhere with internet connection.

- GPS (Global Positioning System): global positioning system that provides the geographic coordinates through a point receiver. Through a search system based on geolocation API, standardized by the W3C, one can check if the computer, laptop or mobile device (phone, PDA, tablet, etc.) has or not a GPS device or system a-GPS (Assisted GPS), which can use different types of data connections to improve performance in the acquisition of the position information. In the absence of the last, the system will use the location by IP. The user may also inform any time, via the interface, his current position or future basis for the calculation of routes and suggestions about the Cup to a specific coverage radius.

\subsubsection{Web Services layer}

The Web Services Layer is composed for components WMS, CSW, IC and VGI presented next:

- WMS (Web Map Service): Web service responsible for displaying geographic maps.

- CSW (Catalogue Service for the Web): Web service responsible for search of metadata into catalog created.

- CI (Context Information): based on an ontological mapping, this Web service provide information relevant to the environment in which determinate user is inserted based in the onlogical model.

- VGI (Volunteered Geographic Information): the user is able to provide new information about a certain location or on events and services linked to a location. To be able to contribute, the user needs to perform a register through an online form, where personal data are collected for validation and posterior access. After perform the proper authentication, the user will be able register information about events on the World Cup, as well as data on support infrastructures such as hotels and restaurants, informing the location within a map available on geoportal. These data are, later, validated and made available by a technical team, aiming to increase the geographical database of 2014 World Cup.

\subsubsection{Data and metadata layer}

The data and metadata layer is composed for Metadata Catalog and for Spatial Database, described next:

- Metadata Catalog: set of metadata that describes available data, including description of VGI.

- Spatial Database: data repository that stores spatial information about locations where occur the World Cup events and also manages the data about preferences of each user. Ontological Model for a Situation-Aware SDI In order to formalize the World Cup environment concepts a domain ontology was developed. The formalization performed generated a context model, here called OntoCopa. This domain ontology provides the necessary support for SDI in the treatment of requests and preferences. The software Protégé [20] was used to develop the ontology. Fig. 4 display the ontology OntoCopa. Were defined classes and subclasses for each concept linked to the World Cup. Each of these classes and their relationships are described below, using some of the categories based on the ontology DOLCE upper level, defined by [13]:

- Abstract - class that corresponds to the concept of intangible entities. Has the class Time as a subclass.

- Time - class that represents the changes and sequence of events in space. The class Interval is its subclass.

- Interval - subclass of Time, which is the difference between final and initial a period of some event.

- Event - class representing some happening in a given place and time being able to have or not the participation of a person. Its subclasses: Collective Football Match and Training.

- Football_Match - subclass of the Event class that represents the concept of realization of a competition between two teams from different countries or clubs scheduled for a given time (Time) and place (location).

- Coaching - Event subclass that represents the preparation of the players and the whole team for the football match.

- Localization - Class styling a given geographic position on the globe determined by coordinates or an 
address.

- Object - the class that calls all things tangible and intangible, concrete and abstract.

- Concrete - subclass of object that specifies objects really exist.

- Interview - subclass of the Event class that represents the meeting of players and coaches to the media that does cover the Cup.

- Agent - Class styling active objects that perform some action. The Social Agent and Person classes are its subclasses.

- Social Agent - class representing active actors in the social environment. Its subclasses are Collective and Organization classes.

- Collective - class that corresponds to the set of social agents. The Football Team class is its subclass.

- Coaching_Staff - Collective subclass that represents the set of auxiliary of a football team.

- Football_Team - Collective subclass that represents the set of players from the same club or team.

- Organization - class representing the concept of a set of social agents, united by common goals and purposes.

- Person - class representing humans. The class Role is its subclass.

- Physical_Structure - class that corresponds to the structures for accommodation, food, transport and recreation for people. Classes Accommodation, Stadium, Transport and Restaurant are its subclasses.

- Accommodation, Stadium, Transport, Food and Cultural Space - subclasses of the Structure class that support visitors, tourists and professionals involved as Cup event.

- Social_Object - class that represents the objects that play a role in the social world. The Role class is its subclass.

- Role - Social Object subclass that corresponds to the responsibilities, rights and duties of an individual in a given environment. Football Player, Supporter and Coach are its subclasses.

- Football_Player - subclass of Role formed by professionals who work in a selection of a particular country.

- Supporter - subclass of Role that corresponds to people who cheer for a football team and participate in events related to it.

- Coach - Role subclass that corresponds to the professional coaching players of a football team.

All relationships are associative, bidirectional, as detailed in Table 1.

Table 1. Ontocopa Model Relationships

\begin{tabular}{|c|c|c|c|}
\hline Class 1 & Relationship & Class 2 & Type \\
\hline Event & Occur & Time & $\begin{array}{c}\text { Associative } \\
\text { Bidirectional }\end{array}$ \\
\hline Event & $\begin{array}{c}\text { Is } \\
\text { performed }\end{array}$ & Location & $\begin{array}{c}\text { Associative } \\
\text { Bidirectional }\end{array}$ \\
\hline Agent & Participates & Event & $\begin{array}{c}\text { Associative } \\
\text { Bidirectional }\end{array}$ \\
\hline Organization & Sponsors & Event & $\begin{array}{c}\text { Associative } \\
\text { Bidirectional }\end{array}$ \\
\hline Physical_Structure & Has & Location & $\begin{array}{c}\text { Associative } \\
\text { Bidirectional }\end{array}$ \\
\hline Agent & Uses & Physical_Structure & $\begin{array}{c}\text { Associative } \\
\text { Bidirectional }\end{array}$ \\
\hline Person & Plays & Role & $\begin{array}{c}\text { Associative } \\
\text { Bidirectional }\end{array}$ \\
\hline Coach & Coaching & Football_Player & $\begin{array}{c}\text { Associative } \\
\text { Bidirectional }\end{array}$ \\
\hline Coaching_Staff & Helps & Coach & $\begin{array}{c}\text { Associative } \\
\text { Bidirectional }\end{array}$ \\
\hline Football_Player & Integrates & Football_Team & $\begin{array}{c}\text { Associative } \\
\text { Bidirectional }\end{array}$ \\
\hline Supporter & Cheers & Football_Team & $\begin{array}{c}\text { Associative } \\
\text { Bidirectional }\end{array}$ \\
\hline
\end{tabular}




\begin{tabular}{l|c|c|c}
\hline Football_Match & Happens & Estadium & $\begin{array}{c}\text { Associative } \\
\text { Bidirectional }\end{array}$ \\
\hline
\end{tabular}

\subsection{Conceptual Model}

The relationships of the ontology ontoCopa were translated in the implementation of a conceptual model, as shown in Fig. 5. This model includes the main classes of domain ontology and its hierarchical and associative relationships with their multiplicity.

Unlike what is done in most conceptual models where roles as "employee", "teacher", "football player" are defined as subclasses of the class "Person", this conceptual model follows the logic of the ontological model where the class "Person" keeps only one associative relationship with the papers involved.

This conceptual model allows implementation of information systems that make use of the navigability between the entities of the ontology, allowing inferences to be made through their relationships. These inferences are essential for the generation of alerts and messages to users, following information contextualized to their preferences and their current environment. This feature gives a sense of greater user familiarity with the system and the return in searches more effective, resulting in increased the SDI reliability.

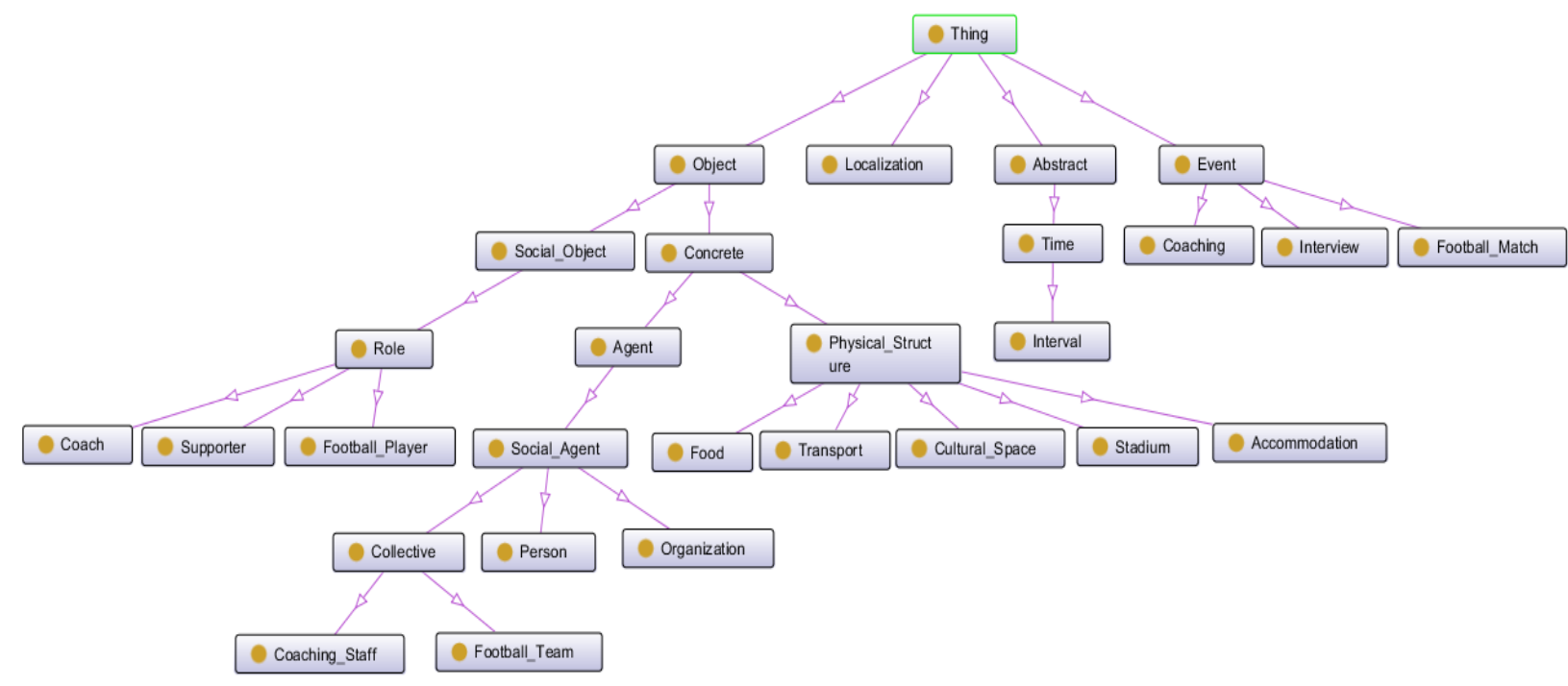

Fig. 4. Context model.

\subsection{GeoCopa 2014 Portal}

A SDI has a set of technologies, services, spatial data and metadata. For all these resources are accessible to users in an easy and simplified way, they are available in a geoportal. The geoportals are websites that gather and organize such geographic resources decentralized through a set of Web pages [3].

The geoCopa geoportal, shown in Fig. 6, was developed to centralize all SDI-geoCopa resources. In its main page, there is a map of Brazil where is possible to search and locate, through a box, each state and the city that hosted the World Cup games in 2014.

The geoportal presents the definition of the problem and the proposed solution, as well as the general and specific objectives of the work by the menu "The Project". From the "The World Cup" provides information about the event and the historical application and choice of host country. The submenu "Host Cities" displays an interactive map where each tag is a link that leads to a brief description of each city and stadium where the games take place.

There are fields in the left menu of the geoportal which facilitate the search for spatial information related to events and host cities of the World Cup. A user can also perform a register of personal information and 
preferences of the user as his team or selection, language, radius and range of research and its current location. So, after one register and authenticate the geoportal will suggest tips on games and other events marking the location on the map with a text box with additional data, as is shown in Fig. 6.



Fig. 5. Conceptual model.


Fig. 6. Geocopa portal.

The geoCopa Portal was developed with JSP (JavaServe Pages) and uses Google Maps API to handle maps and their input and output data. When the user performs the login, the system searches information in the database, according his predefined preferences, and plot them on the map. From user position, the system enables to create routes to host cities and other places. It also shows restaurants, accommodations, and other infrastructures next to these points following the user preferences. For a better user iteration, the points, textbox and other graphical components are loaded in an asynchronous manner using Ajax (Asynchronous JavaScript and XML). 
Through the portal one can also access the system GeoNetwork by menu "Metadata Catalogue", which gives access to the metadata catalog and geographical maps in KML (Keyhole Markup Language) and Shape format. The service display, manipulation and generation of new maps can be accessed through the menu "Data View", where the user have access to a customized version of the open source system I3GEO . This system generates WMS services of the SDI, integrating the set of spatial information together with the INDE. Finally, the menu "Contact" presents project team member.

\subsection{Metadata Manager}

The search and retrieval of spatial information is a major goal of a SDI. When a particular geographical data has only a title without a description of the information it holds, the search becomes more difficult. In this sense, the metadata provide a more detailed spatial data. They allow spatial information can be retrieved in an easier way in terms of number of queries related to spatial data by users or professionals from different areas and interests.

ensure better organization and interoperability between different sources of geographic data around the world were defined various metadata standards such as IS019115 and CSDGM (Content Standard for Digital Geospatial Metadata). As previously mentioned, this work was used as standard the MGB profile and GeoNetwork system to manage the set of data descriptions, i.e., the metadata catalog. These choices are due to a recommendation from INDE both with regard to the MGB profile (approved in 2009 by CONCAR) regarding the use of open source GeoNetwork system, being adherent to the CSW protocol [8].

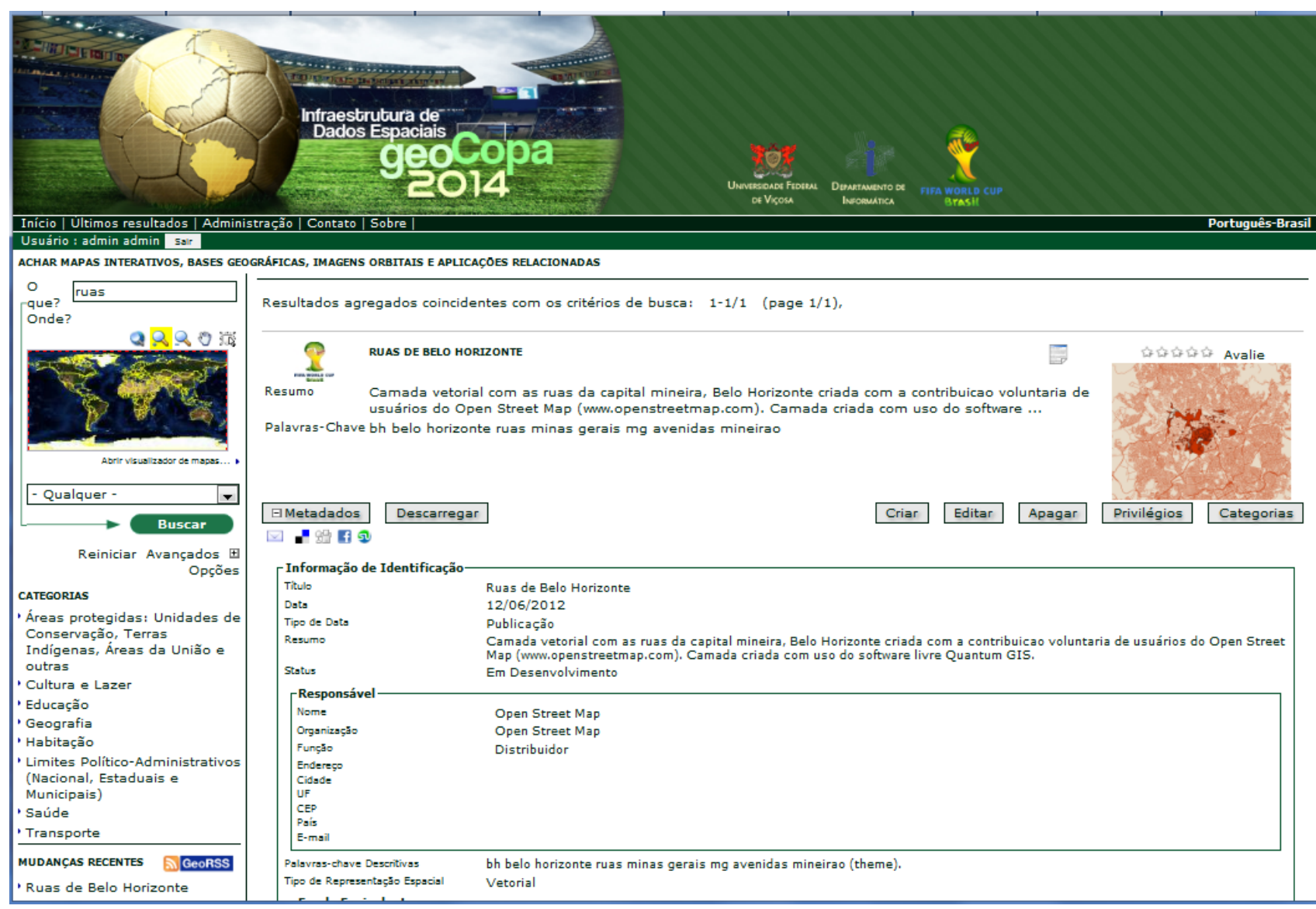

Fig. 7. Metadata manager geonetwork.

Besides catalog metadata, GeoNetwork allows queries on the metadata related to spatial information Cup as, for example, the location of the host cities. The search can be made by title, site, summary, keywords, or even a free text field that matches any of a particular metadata.

Fig. 7 displays the metadata catalog manager, GeoNetwork, configured for SDI-geoCopa. In this same figure are 
shown the metadata for "Belo Horizonte Streets" as the standard MGB profile. The data itself, which in this case would be the shapefiles and KML with their lines, polygons and points, are available for download. In this same page, there is a link where the user is directed to the I3Geo and will be able view and manipulate the maps described by the metadata.

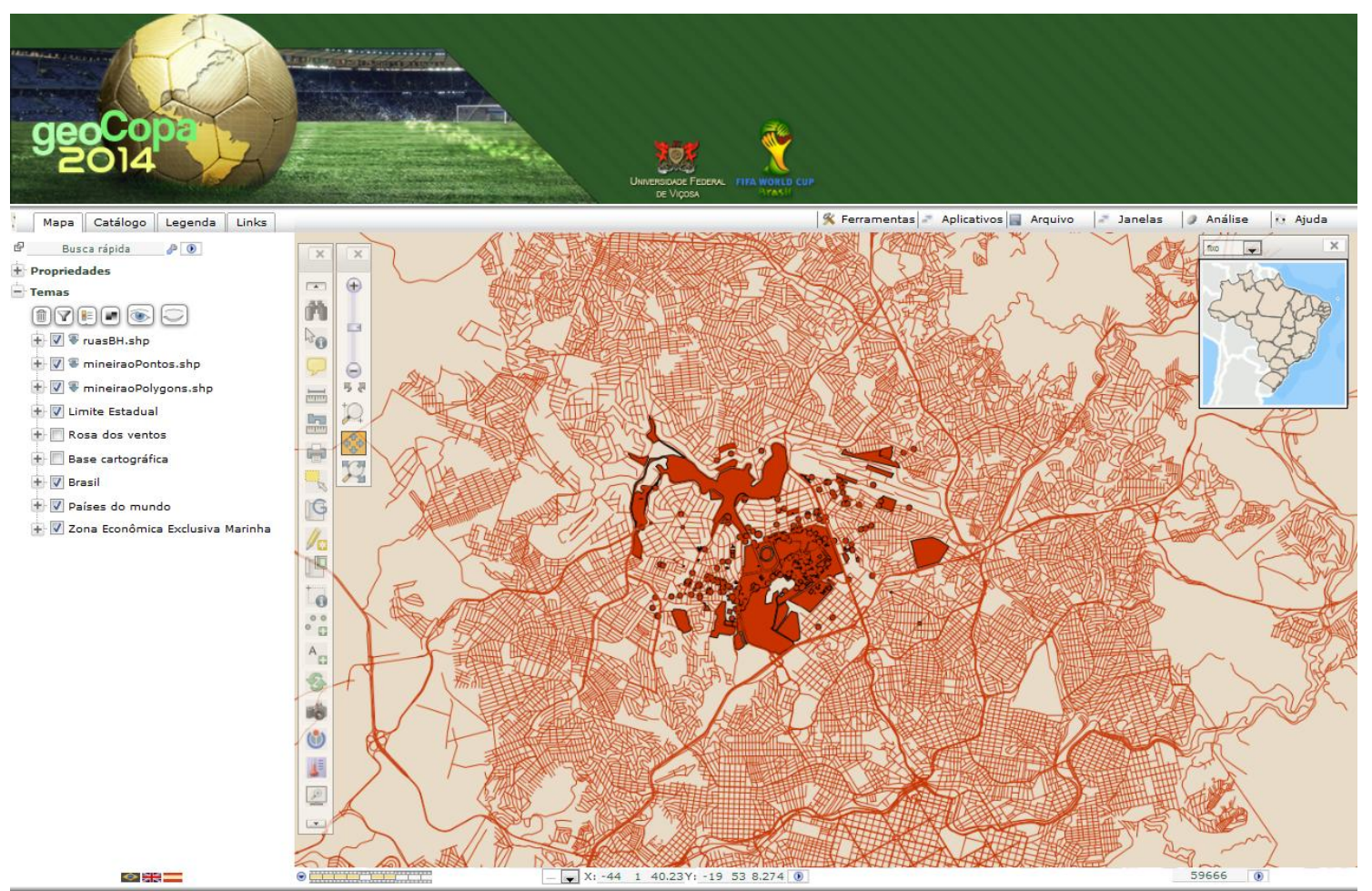

Fig. 8. I3Geo maps viewer.
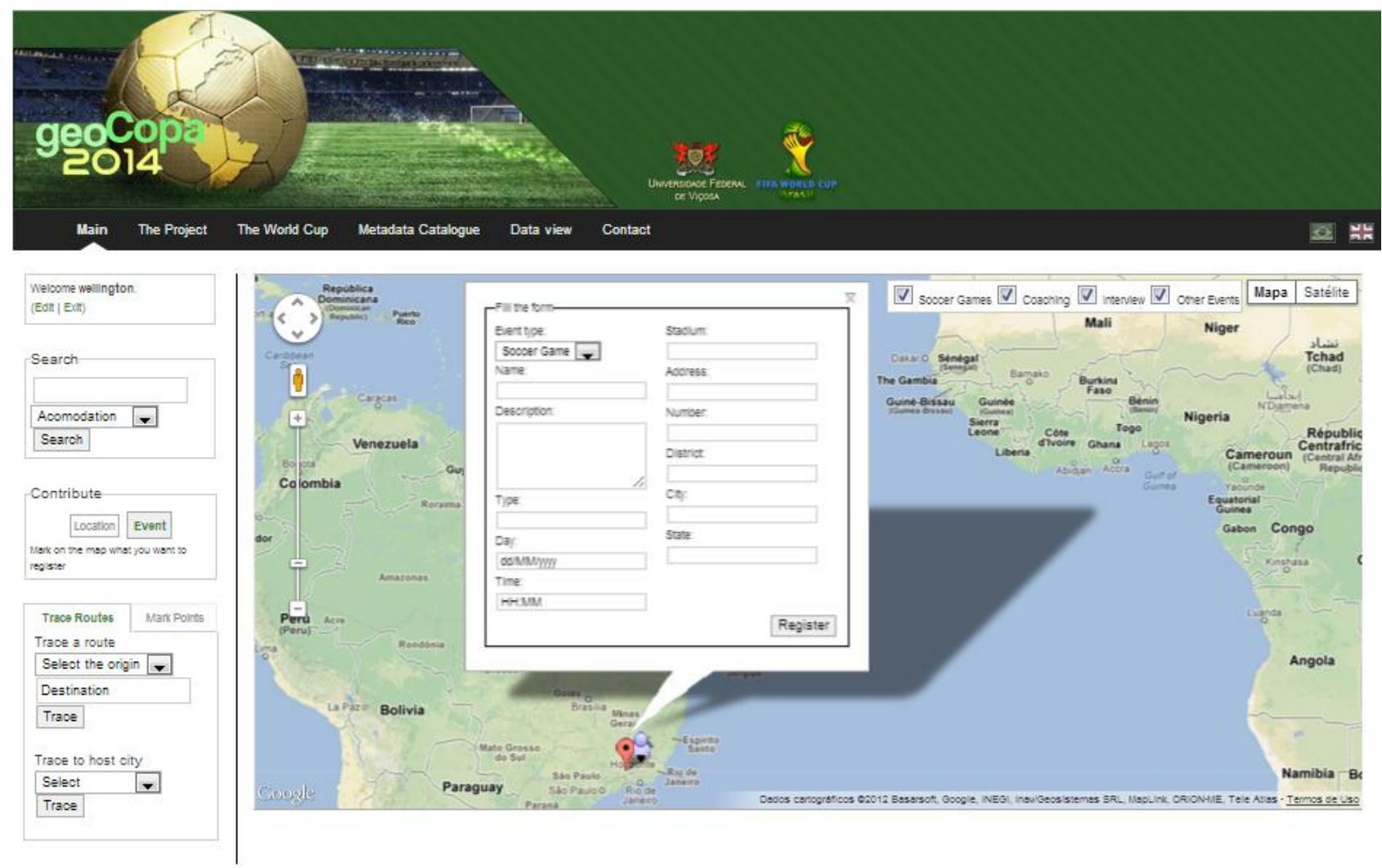

Fig. 9. VGI environment. 


\subsection{Visualization and Manipulation of Maps}

Besides consulting the maps for the main interface of the geoCopa portal, was also made available a link on this same page that gives access to another viewer and also more advanced spatial data handler, the I3Geo. The I3Geo is an application based on MapServer. It was developed for geographic data access and analysis. Through it, the user can generate graphs and charts on demand, overlay maps and perform operations on geographic data. Fig. 8 shows the geographic data viewer I3Geo, configured for SDI-geoCopa.

\subsection{VGI Environment}

The SDI-geoCopa also has a VGI support. The interface showed in Fig. 9 exhibits the environment to VGI. In this environment, users can register new geographical information about events, facilities or services related to the World Cup as football matches, interviews, and places for accommodation or food, among others. To help, the user must first register on the geoportal. After registration and proper authentication, it should click on "Contribute" and report the location he want to include some information available by clicking on the map on the main page. Then he can add or change information on the informed site. All data derived from the voluntary contribution should be analyzed by a technical team before becomes available.

\section{Final Considerations}

A context-sensitive SDI brings great benefits to the users who need information that is actually of interest within the environment where he is. The mapping of the ontological domain of the World Cup includes the related entities that is the starting point for obtaining a broader understanding of the semantic meaning of that domain.

The inferences that can be performed by the navigability between the classes defined in the ontological model and passed to the SDI conceptual model gives the power to anticipate the user's searches and surveys, suggesting event locations or physical structures that may interest them according to the environment of the World Cup and their preferences pre-registered.

The geoCopa portal was presented as handy and useful for non-technical users who need to obtain spatial information about the events linked to the World Cup. For more advanced users, the geoportal provides a metadata catalog manager that allows obtaining geographic data and metadata, and a geographic data handler with overlay options and creating new maps.

Finally, SDI-geoCopa allows user to subscribe voluntarily new spatial information about events, facilities and services related to the World Cup, marking the position of the same on the map and adding details about them.

Future work will introduce the use of semantic reasoners to ensure inferences more accurate within the ontoCopa domain ontology. Further research may also explore the use of filters for VGI, to increase reliability of the information provided. An evaluation and validation process of SDI can also be realized in future investigations. This project can be modified, in easy way, to be used in other international events such as the Olympic Games.

\section{Acknowledgment}

This work was partially financed by CAPES - Coordination for the Improvement of Higher Education Personnel, CNPq - National Council for Scientific and Technological Development of Brazil and FAPEMIG Foundation for Research Support of Minas Gerais State.

\section{References}

[1] Brasil sustentável: impactos socioeconômicos da copa do mundo. (2014). Retrieved 2014, from http://www.copa2014. gov.br/pt-br/sobre-a-copa/copa-de-2014

[2] Chiang, L., \& Hsieh, T. C. (2007). Information integration to create an infrastructure: facilitating public service provisioning in taiwan. Electronic Journal of e-Government, 5(1), 29-42. 
[3] Maguire, D. J., \& Longley, P. A. (2005). The emergence of geoportals and their role in spatial data infrastructures. Computers, Environment and Urban Systems, 29(1), 3-14.

[4] Goodchild, M. F. (2007). Citizens as voluntary sensors: spatial data infrastructure in the world of web 2.0. International Journal of Spatial Data Infrastructures Research, 24-32.

[5] Man, E. D. (2011). Spatial data infrastructuring: praxis between dilemmas. International Journal of Spatial Data Infrastructures Research, 261-289.

[6] Iso, J. N., Zarazaga, S. F. J., \& Medrano, P. R. M. (2005). Geographic Information Metadata for Spatial Data Infrastructures.

[7] Nebert, D. (2004). Developing Spatial Data Infrastructures: The SDI Cookbook, v2. 0. Global Spatial Data Infrastructure.

[8] Decreto no 6.666, de 27 de novembro de (2008). Retrieved 2008, from http://www.planalto.gov.br/ccivil 03/Ato2007-2010/2008/Decreto/D6666.htm

[9] Dessers, E., Rompvoets, J., Janssen, C. K., Vancauwenberghe, G., Vandenbroucke, D., Haverbeke, L. V., \& Hootegem, G. V. (2012). A multidisciplinary research framework for analysing the spatial enablement of public sector processes. International Journal of Spatial Data Infrastructures Research, 125-150.

[10] Rajabifard, A., \& Williamson, I. P. (2001). Spatial Data Infrastructures: Concept, SDI Hierarchy and Future Directions.

[11] Gruber, T. R. (1995). Toward principles for the design of ontologies used for knowledge sharing? International Journal of Human-Computer Studies, 43(5), 907-928.

[12] Kokar, M. M., Matheus, C. J., \& Baclawski, K. (2009). Ontologybased situation awareness. Information Fusion, 10(1), 83-98.

[13] Gangemi, A., Guarino, N., Masolo, C., Oltramari, A., \& Schneider, L. (2002). Sweetening ontologies with dolce, in knowledge engineering and knowledge management: Ontologies and the semantic Web.

[14] Bechhofer, S., Harmelen, F. V., Hendler, J., Horrocks, I., McGuinness, D. L., Schneider, P. F. P., \& Stein, L. A. (2004). Owl web ontology language reference. Retrieved, 2004, from http://www.w3.org/TR/owl-ref/

[15] Doyle, A., \& Reed, C. (2001). Introduction to OGC web services: An OGC white paper. Retrieved, 2001, from http://portal.opengeospatial.org/files/?artifactn id=14973

[16] Weißenberg, N., Gartmann, R., \& Voisard, A. (2006). An ontology-based approach to personalized situation-aware mobile service supply. Geoinformatica, 10(1), 55-90.

[17] Lamas, A. R., Filho, J. L., Oliveira, A. D. P., \& Júnior, R. M. D. A. B. (2009). A mobile geographic information system managing context-aware information based on ontologies. Ubiquitous Computing and Communication Journal, 718-727.

[18] Barth, I. J. (2010). Modelando o perfil do usuário para a construção de sistemas de recomendação: um estudo teórico e estado da arte. Revista de Sistemas de Informação da FSMA, 59-71.

[19] Orshoven, J. V., Bamps, C., Beusen, P., Hall, M., Janssen, K., \& Vandenbroucke, D. (2003). Spatial data infrastructures in europe: State of play spring 2003. Retrieved, 2003, from http://inspire.ec.europa.eu/ reports/stateofplay/rpact3v4.pdf

[20] Knublauch, H., Fergerson, R. W., Noy, N. F., \& Musen, M. A., The protégé owl plugin: An open development environment for semantic web applications. The Semantic Web, 229-243.

Wellington Moreira de Oliveira received his B.S. degree in information systems from Center of Higher Study, in 2006 and He received his M.S. degree in computer science from Federal University of Viçosa, in 2012. He is currently a professor at Computer Science Department, Federal Institute of Southeast Minas Gerais, Brazil and Ph.D. student in computing from Fluminense Federal University. His research interests include provenance of scientific experiments and spatial data infrastructure. 
Jugurta Lisboa-Filho received his bachelor and master degree from Federal University of Rio de Janeiro in 1983 and 1992, respectively, and Ph.D degree from Federal University of Rio Grande do Sul in 2000. He is an associate professor in Department of Informatics, Federal University of Viçosa, Minas Gerais, Brazil. His entire major are computer science. His research interests include geographic database design, spatial data infrastructure and reuse mechanism.

Alcione de Paiva Oliveira received his B.S. degree in oceanography from University of Rio de Janeiro State, in 1985. He received his M.S. degree in computer science from Military Institute of Engineering, in 1990. He received his Ph.D. degree in computer science from Pontifical Catholic University of Rio de Janeiro, in 1996. He is currently an associate professor in Department of Informatics, Federal University of Viçosa, Minas Gerais, Brazil. His research interests include artificial intelligence, ontology, and multiagent systems.

Wagner Dias de Souza received his bachelor and master degree in computer science from Federal University of Viçosa, in 2011 and 2013. respectively. He is currently a professor in Rural Federal University of Rio de Janeiro, Seropédica, Rio de Janeiro, Brazil. His research interests include geographic information systems, spatial data infrastructure and volunteered geographic information.

Lucas Francisco da Matta Vegi received his B.S. degree in information systems from Faculdade de Minas, in 2009 and He received his M.S. degree in computer science from Federal University of Viçosa, in 2012. He is currently a professor in Federal Institute of Southeast Minas Gerais, Brazil. His research interests include software engineering, mechanisms for reuse in software development process and mobile computing.

João Rodrigo Menighin de Oliveira is a graduate student in computer science at Federal University of Viçosa. He had a scholarship granted by the Conselho Nacional de Desenvolvimento Científico e Tecnológico (CNPq) in this project. 